\title{
O MUNDO CAÍDO: UM CONCEITO ANALÍTICO PARA O PECADO
}

THE FALLEN WORLD: AN ANALYTIC CONCEPT FOR SIN

Idilio Oliveira de Araújo ${ }^{89}$

${ }^{89}$ Doutorando pela UMSA graduado em direto pela UNNCAP. Especialista com Magistério Superior em Direto Penal e Processual Penal pela UPPESCES. Pós-graduado pela Universidade de Coimbra em Direito Penal Econômico e Europeu. Pós-graduado pela Esmape Magistrado (T.PE). Bacharelando em Teologia pela Faculdade Internacional Cadade Vwa. Emalli idlitioolivera@hotmail.com 


\section{RESUMO}

É comum o pensamento em que se julga uma conduta que não se enquadra em determinado mandamento divino como pecado. Argumenta-se que não existe pecado maior ou menor e que pecado é pecado e tem como consequência a morte espiritual. A partir desse pensamento desenvolvo o conceito analítico de pecado, não como um ato, mas como um percurso, com suas atenuantes, agravantes e consequências. O presente artigo faz uma análise da Teoria Formal do Crime e a partir deste ponto controvertido fixa o conceito analítico de pecado. Ilustro o tema descrevendo a visão de John Piper sobre a graça futura e a sua relação com um dos elementos do conceito de pecado bem como a resposta de Zaffaroni sobre conduta humana. $\mathrm{O}$ tipo de pesquisa utilizado foi pura, com abordagem qualitativa, fazendo uso da técnica de revisão bibliográfica.

\section{PALAVRAS-CHAVE}

Pecado; atenuantes para o pecado; penas decorrentes do pecado.

\section{ABSTRACT}

It is common to think of a conduct that does not fit into a particular divine commandment as sin. It is argued that there is no greater or lesser sin and that sin is sin and results in spiritual death. From this thought I develop the analytical concept of sin, not as an act, but as a course, with its attenuating, aggravating, and consequential consequences. The present article makes an analysis of the Formal Theory of Crime and from this controversial point fixes the analytical concept of sin. I illustrate the theme by describing John Piper's vision of future grace and its relation to one of the elements of the concept of sin as well as Zaffaroni's response to human conduct. The type of research used was pure, with a qualitative approach, making use of the bibliographic review technique.

\section{KEYWORDS}

Sin; extenuating of sin; of sin. 


\section{INTRODUÇÃO}

Na função judicante, pude me deparar com condutas que, inicialmente e vistas por olhos deslocados de uma minudencia efetiva, tratavam-se de atos hediondos que deveriam sofrer punições severas à luz do direito penal. Levadas a julgamento, analisando os elementos do crime e aplicando-os àquelas condutas, pude, inúmeras vezes, verificar que os autores estavam amparados pela lei e que justificavam os seus atos legalmente, outras vezes, carecia-se de uma efetiva conduta humana ou que tais condutas não eram reprováveis na visão jurídica e por consequência, absolvi àqueles levados à julgamento. Ora, o ofício do Magistrado não deve se desviar do ordenamento jurídico, principalmente quando é questão de coisa de tão grande monta, isto é, quando se trata da liberdade do ser humano. E o ofício do Cristão? Diante do mandamento probatório (BAVINCK, 2012), pode se desviar das Escrituras Sagradas notadamente quando se trata de pecado e salvação?

Pois bem, comecei a perquirir sobre condutas, que vistas por olhos não atentos às Escrituras ${ }^{90}$ serão consideradas pecados e por analogia conclui que: se a Justiça do homem analisa a conduta levada a julgamento, pondera suas atenuantes, agravantes e até mesmo da possibilidade da ação ter sido de acordo com o direito ou sem culpabilidade, o que se dirá da Justiça Divina? Seria possível sob o foco da lente da cosmovisão cristã, visualizarmos condutas que a princípio seriam consideradas pecados e nos depararmos com condutas que não são pecados segundo a revelação Divina?

Se prescindirmos da Bíblia e lançarmos uma pergunta sobre conduta social reprovável, não necessitamos muita penetração para percebermos que não há nada em comum entre a conduta de quem apenas deseja o mal a alguém e quem comete um homicídio, isto é, que se trata de duas ações com significado social completamente distintos. No campo do Direito, a segunda conduta está tipificada na lei penal e tem como consequência uma pena, na Bíblia, ambas as condutas estão normatizadas como pecados e também com consequências implícitas e explícitas. $O$ traço em comum entre essas duas condutas é que ambas são

\footnotetext{
${ }^{90}$ Aqui enfatizo a conduta do Cristão no Novo Testamento, que deve ser conduzida pelo amor ágape.
} 
apenadas (e aqui considero as consequências do pecado uma pena) enfocando a lei penal e as Escrituras, entretanto, para ambas, e nos dois códigos de conduta ${ }^{91}$, o crime ou o pecado é um caminho a ser percorrido e que incidem nas suas consequências, as atenuantes. É exatamente esta hipótese que iremos analisar.

Não abordaremos a origem nem tampouco os tipos e graus de pecado, pois não cabem neste estudo. Focaremos o pecado na narrativa bíblica, visto que segundo Bavinck, a origem do pecado é um mistério e o mundo caído no qual vivemos se apoia nos fundamentos de uma criação que era boa (BAVINCK, 2012, p. 25). Para Goheen (2016), homens e mulheres foram criados com a capacidade de escolha e Bavinck (2012) analisa o pecado como um ato de vontade. Ainda, calcificamos a nossa pesquisa no escólio de Louis Berkhof (2012) para quem há punições que são resultados naturais do pecado que podem ser abrandadas e até neutralizadas pelos meios que Deus colocou à nossa disposição. Pois bem, baseado nestas informações, iremos abordar a teoria do pecado pela lente da Cosmovisão Cristã com ênfase na Graça Futura. John Piper (2009, p.69) assim descreve a Graça Futura:

A graça não é meramente uma realidade passada, mas também futura. Todas as vezes que eu tomar a Bíblia na mão, a graça de Deus será uma realidade que vai fluir para mim. Todas as vezes que eu colocar a Bíblia novamente na mesa para me ocupar com os afazeres diários, a graça de Deus irá comigo. É isso que eu quero dizer com graça futura. (PIPER, 2009, p. 69)

Iniciaremos revisitando a criação, logo em seguida, enfatizaremos a conduta do homem na perspectiva do direito penal quando volitiva e que enseja responsabilidade. Abordaremos o pecado não apenas como um ato voluntário e livre na escolha, mas como um percurso que se levará em consideração além do ato de vontade, a possibilidade de ser anticristã e culpável, na perspectiva de possibilidades de escolhas diversas de condutas.

\footnotetext{
${ }^{91}$ Observe que aqui, considero apenas um dos aspectos da Bíblia, o de Código de conduta moral.
} 
Por derradeiro, analisaremos as consequências do pecado na ótica cristã e fundada nesta pesquisa.

De proêmio esclareço que anticristã é ser contrário ao amor, afinal, o caminho que conduz à vida é um caminho de amor, não só de perseverança - amor por outras pessoas. Jesus disse: "Com isso todos saberão que vocês são meus discípulos, se vocês se amarem uns aos outros"92. E João disse: "Sabemos que passamos da morte para a vida, porque amamos nossos irmãos"93. O amor encarnado na fé e fé sem obras será apenas: a fé em si, no dizer de Tiago ${ }^{94}$, fé morta.

\section{REVISITANDO GÊNESES 1.26}

A Teologia Reformada sustenta que Deus pode ser conhecido, mas que ao homem é impossível ter um completo e perfeito conhecimento de Deus (BERKHOF, 2012). O homem não pode conhecer-se à parte do conhecimento que Deus Ihe dá de si mesmo, é que em conhecendo a Deus, cada um de nós também a si se conhece (BIÉLER, 2012), e no dizer de Goheen (2016, p.13), “a vida consiste - ou deveria consistir - em conhecer a Deus profundamente". Jesus em oração afirma que a vida eterna é conhecer a Deus ${ }^{95}$. Pois bem, o conhecimento que temos que minudenciar a respeito de nós mesmos é duplo a saber: em um, a criação perfeita e boa ${ }^{96}$ e em dois, a queda do homem ${ }^{97}$. Isso nos remete a narrativa bíblica da Criação, Queda e Redenção e ao homem recriado à imagem de Deus na pessoa de Jesus Cristo. De proêmio devemos enfatizar que a narrativa inicia com a criação de todas as coisas e em Gênesis observamos que com frequência Deus afirma que tudo era bom "e viu Deus que isso era bom", além da magnitude da soberania de Deus revelada no ato costumeiro da época em dá nome ao que se cria, e no ápice da criação, Deus criou

\footnotetext{
${ }^{92}$ João 13,35

93 1João 3,14

${ }^{94}$ Tiago 2,17

${ }^{95}$ João 17,3

${ }^{96}$ Gênesis 1,26

${ }^{97}$ Gênesis 3
} 
o homem à Sua imagem e semelhança, impondo um mandato cultural à criatura de dominar ele sobre todas as coisas sujeitandoas. ${ }^{98}$

\section{O CONCEITO DE PECADO}

Goheen (2016) conceitua o pecado como a corrupção da boa criação. O pecado é um ato de vontade, uma conduta humana (observar os casos de conduta omissiva alhures) livre com o fim de fazer o mal ou que por violação do dever de cuidado, causa sofrimento ao homem, anticristã, pois é contrária ao amor e que o pecador tenha tido a possibilidade exigível e livre de atuar de outra maneira.

Essa definição de pecado, nos permite valorar se uma determinada conduta é considerada pecado e com isso causa sofrimento ao homem e à natureza, colocando-o em um estado infeliz por descumprir o mandado cultural determinado em Genesis $^{99}$. Em primeiro lugar, devemos perguntar se houve conduta voluntária livre, porque se falta o caráter genérico do pecado, então nos encontramos diante de uma ausência de conduta, e na ausência de conduta, não há pecado. Evidentemente não podemos confundir com os casos de conduta por omissão, que analisaremos oportunamente. Em seguida devemos questionar se essa conduta foi anticristã, ou seja, se a conduta voluntária livre foi contrária ao amor e com isto terá o poder de causar sofrimento. Sendo a conduta livre, contrária ao amor, resta saber se o autor do ato, tinha a possibilidade psíquica de atuar de outra maneira. Se tinha, estaremos diante de uma imperfeição que, portanto, irá causar sofrimento, colocando-o em um estado infeliz inerente ao grau de sua conduta. O pecado é um ato de vontade, e que por assim ser, se dirige ao objeto da conduta, alterando-o. Evidentemente que o pecado ou conduta voluntária livre, é limitado pelo ato de conhecimento do homem, que fornece dados no exato momento da prática do ato voluntário e livre para agir de acordo com o bem ou mal que lhe é inerente, mas a cristologia não altera o objeto, apenas fornece dados, pois este existe fora do homem e antes do conhecimento ou do seu

\footnotetext{
${ }^{98}$ Gênesis 1.28

${ }^{99}$ Gênesis 1.28
} 
potencial cristão. A felicidade perfeita está ligada à perfe ição, quer dizer à depuração completa do homem, portanto o pecado é conduta inerente à queda e o pecador sofre pelo mal que praticou.

Calvino (BIÉLER 2012) explica o caráter hereditário e inelutável deste pecado e a divina maldição que ele suscita. Vejamos:

O homem, em sua totalidade, com seus pertences, seus atos, seus pensamentos, suas palavras, sua vida, tem desagradado absolutamente a Deus, como se houvesse se tornado seu especial inimigo e adversário, até dizer que se arrependia de havê-lo feito. Após ter sido lançado em tal confusão fez-se fecundo em sua maldita sementeira, para engendrar geração semelhante a ele, isto é, viciosa, perversa, corrompida, vazia e destituída de todo bem, rica e abundante em mal (BIÉLER, 2012, p. 247)

O pecado que corrompe a liberdade não é um poder fatal que suprime a responsabilidade do indivíduo: "O que constitui o estado de perversão radical e inelutável do seu humano é a anuência voluntária e atual que ele dá à revolta impressa no fundo de seu ser pela hereditariedade" (Biéle, 2012, p. 248).

O pecado atinge o homem no seu todo e contamina e desfigura cada milímetro da criação, alcançando e deformando também a criação não humana. O apóstolo Paulo explica ${ }^{100}$ que a criação ficou sujeita a inutilidade, não por sua vontade, mas por causa daquele que a sujeita, pois toda a criação geme e agoniza até agora como se sofresse dores de parto. O mau mordomo deixou de cumprir o mandado cultural por excelência. Mas apesar disto, ainda é possível encontrar a honestidade, o amor e a alegria no mundo. Deus não abandona a obra de suas mãos; algo de bondade original da criação ainda pode servisto. A essa prova da influência restringente de Deus sobre o pecado, Calvino chama de Graça geral, outros teólogos de Graça comum. Mas isso é tema para outro artigo.

\footnotetext{
${ }^{100}$ Romanos $8.20-22$
} 


\section{A CONDUTADO HOMEM}

O homem pratica atos: de vontade e de conhecimento. O ato de vontade é o que se dirige ao objeto alterando-o e o ato de conhecimento é o que se limita a fornecer dados ao observador, sem alterar o objeto (ZAFFARONI, 1999). A conduta que deve ser considerada humana para os efeitos desta pesquisa é o ato de vontade, pois este é que modifica o mundo, que transforma.

No escólio de Goheen (2016, p. 68), homens e mulheres foram criados por Deus com a capacidade de escolha. A convivência social é um dos meios de atuação do homem com a possibilidade de escolher não obedecer em sua resposta livre. É oportuno observar que nós temos e mantemos, também, uma relação social unilateral: $O$ arrependimento por exemplo, além de condição para a efetivação do perdão divino, (e aqui abro uma discussão no que se refere a João 8.11 se Jesus teria perdoado sem o efetivo arrependimento da mulher adúltera) é uma forma de relação social unilateral por excelência, pois é uma convivência do homem com ele mesmo e o primeiro passo para a reforma moral para implementarem a ordem divina em situações históricas e culturais específicas.

O homem evolui em sabedoria (aqui deixo evidente que a evolução a que me refiro é o conhecimento de Deus) e quanto maior o saber, maior a responsabilidade e é exatamente a responsabilidade que condiciona o saber e o reconhecimento da parcialidade de todo o conhecimento. O homem pratica atos de vontade, alterando uma situação ou um objeto, através de atos do conhecimento, que não altera o mundo, sendo este, criação perfeita da mordomia humana. A vontade ou a capacidade de escolha é um aspecto importante da imagem de Deus em nós e o conhecimento é o grau de decisão ou evolução do homem (o conhecimento de Deus).

A sua vontade está ligada e será determinada pelo seu conhecimento. Não há pecado sem um ato de vontade. O pecado não é algo distinto da conduta. Voluntário é o querer ativo, o querer que muda algo. A vontade sempre tem um conteúdo, que é uma finalidade. Para que haja conduta basta que haja vontade. (ZAFFARONI, 1999) Portanto, a conduta humana é o primeiro elemento a ser analisado para se saber se há pecado. Não existindo conduta humana (que terá que ser voluntária posto que conduta involuntária não será considerado conduta humana) não 
existirá pecado. Mas existindo conduta humana temos que continuar analisando os demais elementos do conceito analítico do pecado: Uma conduta humana volitiva, anticristã e culpável.

\section{A CONDUTA HUMANA ANTICRISTÃ}

Devemos ter em mente que uma conduta anticristã é uma conduta contrária ao amor de Cristo e não surge de uma ordem ou imposição de Deus, mas é uma característica que tem uma conduta de ser contrária às consequências da conversão genuína. Aqui recorremos a Paulo quando minudencia o que é uma conduta humana Cristã. A obediência cristã pela fé na graça futura nos leva a praticar condutas cristãs, ou seja, conduta baseadas no amor ou pelo amor. Segundo Piper (2009, p. 44) "a obediência Cristã é chamada obra de fé". O Cristão deve agir sendo capaz de transbordar do amor da generosidade e em todos os seus atos o amor deve se materializar. Piper nos dá a chave para o amor:

A chave para o amor e a generosidade não é olhar primordialmente para a graça passada e para tudo que Deus fez por você - por mais precioso e indispensável que isso seja. A chave é voltar-se da glória e das garantias da graça passada e depositar a fé firmemente na graça futura (PIPER, 2009, p. 73).

Uma conduta humana anticristã não observa as regras do amor que devem seguir o cristão pela fé na graça futura. Devemos recordar as confissões reformadas que dizem que a fé justificadora não está somente acompanhada de boas obras, mas é também, de alguma forma, a causa instrumental dessas obras.

Ora, sendo a conduta humana e anticristã, e aqui chamaremos tal complexidade de injusto moral, ainda não estaremos diante de um pecado. Nos resta analisarmos o terceiro elemento do pecado, qual seja: a culpabilidade. Evidente que, sendo a conduta Cristã (no contexto aqui enfatizado) não estaríamos diante de um pecado. 


\section{A CULPABILIDADE}

Pois bem, cabe-nos analisar se o autor daquele injusto moral, poderia agir livremente de outra forma ou praticar uma outra conduta. Chegamos ao conceito menos debatido na teoria do pecado. Até aqui a voluntariedade esteve presente, mas na culpabilidade a enfrentaremos de forma mais contundente. A culpabilidade é a reprovabilidade ao autor. O que lhe é reprovado? A sua conduta voluntária e contrária ao amor. Porque se lhe reprova? Porque não se motivou no amor. Porque se lhe reprova não haver se motivado no amor? Porque lhe era exigível que se motivasse no amor, pois que é um cristão.

Assim, se um cristão com uma certa proximidade com Deus furta, sem que ninguém o obrigue a isto ou o ameace e sem estar mentalmente enfermo, dizemos que este sujeito podia motivar-se no amor que proíbe furtar, e que lhe era exigível que no amor se motivasse, porque nada o impedia. Por esta razão sua conduta é reprovável e é culpável perante a lei de Deus. Estamos diante do pecado.

Zaffaroni analisa Aristóteles e a culpabilidade pela conduta de vida nos seguintes termos:

Para Aristóteles, a personalidade que se afasta da virtude escolhe a si mesma. Segundo ele, o homem que se afasta da virtude, vai caindo numa vertente de vício que em determinado momento já não the deixa qualquer liberdade para ser virtuoso, porque com seus atos anteriores, procedeu como aquele que joga uma pera e depois não é capaz de detê-la. (Zaffaroni, 1999 p. 609)

Mas, quais os requisitos da culpabilidade? Em quais situações a conduta contrária ao amor não é reprovável, portanto não será pecado?

São requisitos gerais da reprovabilidade, que tenha sido exigível do sujeito a possibilidade de compreender a reprovabilidade de sua conduta e que as circunstâncias em que se agiu não Ihe tenha reduzido o âmbito de autodeterminação além de um limite mínimo e a possibilidade de agir ou motivar a sua ação 
no amor encontre-se acima do limite mínimo de exigibilidade. Explico: o sujeito pode agir voluntariamente e praticar uma ação contrária ao amor, por falta de capacidade psíquica suficiente para entender a desprovisão de amor de sua conduta ou porque se encontra em um estado de erro acerca da proibição da sua conduta. Zaffaroni (2009, p. 613) diz que igualmente, "o umbral mínimo de exigibilidade não se alcança quando o autor encontrase em uma situação de necessidade exculpante".

Pois bem, vamos entender através de exemplos: Você leitor tem a sua casa invadida por um assassino que com a arma em punho ameaça estuprar a sua filha menor, você imediatamente reage e mata o agressor. Apesar de ter cometido uma conduta voluntária e contrária ao amor, não teria agido em pecado pois que sua conduta não é culpável (observe que de acordo com a Teoria do crime, no direito penal, você teria agido em legitima defesa de terceiros e não seria crime a sua conduta). Analisando a mesma conduta sob a ótica da teoria do pecado, a conduta não seria considerada pecado, pois você não tinha possibilidade de agir de forma diversa e, portanto, não teria culpa, assim não satisfazendo o terceiro elemento do conceito analítico de pecado, apesar de ter sido uma conduta humana voluntária e anticristã.

Outro exemplo seria o caso de um louco matar alguém. Ele agiria voluntariamente e praticaria uma conduta contrária ao amor, mas não teria culpabilidade, pois não entenderia o caráter pecaminoso da sua conduta, portanto não estaria em pecado.

Pois bem, concluímos que para que uma conduta humana ser considerada pecado, necessário será que satisfaça os três elementos do conceito analítico de pecado: Uma conduta humana voluntária, anticristã e culpável.

Nos resta analisarmos de forma não minudente as consequências do pecado, o que faremos a seguir.

\section{OS vícios}

O vício é um ato de vontade, uma conduta livre que causa um mal, causa sofrimento ao próprio viciado, anticristã, pois é contrária ao amor e que o viciado tem a possibilidade livre de atuar de outra maneira, portanto é um pecado. O vício permite uma luta interior no espírito, dele com ele mesmo. Ora, analisando-se o 
caso, aplicando-se o grau de conhecimento de Deus do viciado, a pena é tanto maior quanto maior essa proximidade, o pecador tem vergonha da sua conduta em proporções diretas ao seu desenvolvimento (e aqui minudencio que desenvolvimento moral é a proximidade maior ou menor de Deus). $O$ arrependimento aqui não é o primeiro passo para o refazimento do pecador, e sim, quando associado a determinação em mudar, a força, a fé. O poder transformador da fé na graça futura possui a satisfação libertadora que a graça futura mantém no coração. (PIPER, 2009) No vício, a tríade, arrependimento, expiação e reparação são analisados sob enfoque diferentes, em verdade, primeiro se busca a cura através da vontade incondicional de mudar, é o arrependimento fundado na fé, depois busca-se o fortalecimento para o enfrentamento do vício, aqui temos a expiação, a abstinência do vício, e em um terceiro momento convive-se em meio a viciados para reparar os seus erros, os seus vícios. O vício é o pecado pela não observação dos deveres de conduta do homem e traz como pena sublime, habitar na terra de Node ${ }^{101}$, que é um lugar longe da presença de Deus.

\section{O PECADO POR OMISSÃO}

A omissão é uma conduta ativa que consiste em não fazer o que se teria a obrigação de fazer. Logo, a omissão em si mesma não existe, pois somente a omissão de uma ação determinada pela lei do amor configurará a essência da omissão. Configura-se pecado por omissão quando o Cristão não faz o que pode e deve fazer, que lhe é moralmente cobrado. Logo, o pecado por omissão consiste sempre na omissão de uma determinada ação que se tinha a obrigação de realizar e que podia fazê-lo. John Piper (2009, p.14) afirma que "a fé justificadora sempre está acompanhada de boas obras e também é a causa instrumental dessas obras". Não fazer o bem que se poderia fazer é o resultado de uma omissão. Se toda omissão é uma fonte de sofrimento, o homem deve sofrer não apenas por todo o mal que fez, mas por todo o bem que poderia fazer, e não fez.

${ }^{101}$ Gênesis 4.16 


\section{A PENA}

Como formular uma teoria da pena para o pecado? Bavinck (2012, p. 174) enumera as punições que Deus ordenou para o pecado nesta vida, quais sejam: "culpa, corrupção, sofrimento, morte e domínio de satanás". Evidente que neste artigo, não estudaremos os tipos de pena para o pecado, o que se evidencia pela sua natureza. Vamos focar apenas no sofrimento e morte.

E você receberá o castigo de sua idolatria. Assim inicia Goheen (2016, p. 83) quando analisa a consequência do pecado, que embora seja primordialmente uma ofensa contra Deus, também é uma ofensa contra a criação. Todo pecado está ligado a uma pena, a uma consequência deplorável, a um sofrimento e, portanto, carrega consigo o seu próprio castigo. O inferno, pois é a soma desses pecados, dessas imperfeições. Na terra, o homem mortal, ao cometer um delito, àquela sua conduta se está previsto uma pena, que poderá ser minorada se for observado que para aquela conduta existem atenuantes a serem observadas ou causas de diminuição de pena. No plano de Deus, cada pecado carrega consigo o seu próprio castigo, e sendo a justiça de Deus infinita, os sofrimentos são atenuados pela ação do bem, por toda qualidade adquirida, não há uma única boa ação, um único bom movimento da alma, o mais leve mérito que seja perdido. Toda pena é temporária, no mundo dos homens, o limite da pena está previsto em seus códigos, e para Deus, o limite está subordinado ao arrependimento e a uma ação, sendo esta, seguir Jesus e à restauração de toda boa obra da criação, que depende da vontade inicial. Tal é a lei da justiça Divina: a cada um segundo suas decisões.

Portanto, mesmo após cometer um pecado, o homem está sujeito a um juízo de Deus e sofrerá a consequência da sua ação de acordo com a análise minudente de cada caso, levando-se em consideração vários fatores que poderá levar a uma atenuação nas consequências do ato.

\section{O PERDÃO, A ATENUANTE POR EXCELÊNCIA}

O perdão é uma medida que está ligada diretamente à ofensa. O perdão por ser um ato extremo de amor, atenua a pena 
do pecador. A expiação, por ser uma das fases da aplicação da pena, varia segundo a natureza e a gravidade da falta, do pecado, o mesmo pecado, assim, pode dar lugar a expiações diferentes, segundo as circunstâncias atenuantes ou agravantes, consideradas em cada caso. Evidentemente que perdoar é o desmontar do ódio, é a atenuante por excelência. Em verdade, não é o ato de esquecer a ofensa, é não ver a ofensa. É amar o pecador pois a fé atua pelo amor ${ }^{102}$.

\section{O ARREPENDIMENTO}

O arrependimento, que é um ato de vontade livre, é condição para a salvação e conduz a restauração. No Evangelho de Mateus, João Batista batiza com água para arrependimento ${ }^{103}$. Observe-se que não é causa atenuante do pecado, pois a causa atenuante é levada em consideração para a aplicação da pena, e o arrependimento é observado como causa posterior a aplicação da pena já na fase da execução. Apenas o arrependimento com Cristo pode anular o efeito do pecado, ou da pena. Ocorre que o arrependimento leva à restauração de forma irrefragável. A restauração, que é a aplicação da pena de forma direita, consiste nos sofrimentos físicos e morais. É evidente que as causas e os efeitos do pecado se direcionam para além da expiação. A necessidade da restauração é um princípio de moral e que está latente no homem e exsuge do arrependimento e se fundamente na graça futura. As promessas condicionais da graça ou graça futura estão entretecidas em todo o ensino do Novo Testamento acerca de como devemos viver a vida cristã (PIPER, 2009) mas também aqui temos um tema para outros estudos.

A restauração tem o efeito contrário à ação má, portanto a reparação é a boa ação, é o desfazer o mal, é o bem por excelência. A reparação, é na linguagem sagrada, a salvação, só é realmente importante para aqueles que desejam salvar-se para aqueles que desejam a reparação, e só desejam a reparação aqueles que se arrependeram, em sendo assim, o arrependimento é o início da salvação, o início da reparação. Cessada a febre da

102 Gálatas 5,6

${ }^{103}$ Mateus 3,11 
loucura e da rebelião, o culpado volve ao remorso e à penitência. Aqui relembro o pecado de Davi quando comete adultério com Bate-Sabe e depois trama o assassinato de seu marido. Mas Natã, o Profeta, fica sabendo dessas coisas e confronta Davi por meio de uma parábola (2 Sm. 11-12). A história convence Davi de seu pecado. Ele chora por sua culpa diante de Deus, se arrepende e é perdoado. Mas segundo suas ações têm consequências trágicas. $O$ filho concebido da união adúltera de Davi com Bate-Seba morre. Estupro, assassinato e rebeldia irrompem na própria família estendida de Davi. Finalmente o juízo divino sobre Davi atinge o seu ápice com a morte do filho amado de Davi, Absalão, que tentou tomar para si o trono de Israel. (GOHEEN, 2017)

Embora a diversidade das penas seja infinita, pois infinitos são os atos, estas são inerentes ao ato do pecado. A prisão do homem por um certo tempo, é medida extrema, mas necessária, para fazer cessar a sua maldade por um período de tempo necessário ao refazimento de suas vítimas, quando estas buscam se desfazer das suas imperfeições por efeito de sua vontade. Evidentemente estas prisões não permitem ao homem pecador a sua salvação, é um período de suspensão e não de interrupção da maldade inerente ao pecador infeliz. Para Bavinck (2012) na punição do pecado, o sofrimento serve não somente como punição, mas também como julgamento, como castigo e como educação.

A justiça humana quando aplica a pena ao homem culpado, analisa as circunstancias judiciais que se deu o crime, isto é a culpabilidade, os antecedentes, a conduta social, à personalidade do agente, aos motivos, às circunstâncias e consequências do crime, bem como ao comportamento da vítima, e então, aplica uma pena que serve de base para, levando-se em consideração possíveis atenuantes e agravantes e causas especiais de aumento e de diminuição de pena, que estão previstas para cada crime, chegar-se a uma pena definitiva. Mede o crime pelo próprio crime, atinge indistintamente, sem perquerir sobre a educação do homem, o seu conhecimento, o seu desenvolvimento moral. Para a justiça divina, a graça atinge a todos em forma de graça comum e a cada um em particular em forma de graça salvífica como as causas de aumento e de diminuição de pena correspondentes ao grau de arrependimento dos seres às quais são infligidas as penas. A quem muito foi dado muito será cobrado. 


\section{CONSIDERAÇÕES FINAIS}

Para finalizar, dois aspectos devem ser ressaltados: Primeiramente que o pecado é um ato de conduta humana que contraria o dever de amar do cristão e que ele, de acordo com a sua vontade livre, poderia agir de outra forma. Em segundo lugar, deve-se destacar que mesmo uma conduta sendo considerada pecado, sob ela incidem atenuantes verificáveis na revelação divina e que o perdão é a atenuante por excelência.

Para os cristãos, não são mais as trevas que os castigam, mas a acuidade da luz espiritual que atravessa a inteligência e o faz sentir a angústia da sua falta. A luz que tortura o cristão culpado é a luz do desenvolvimento da sua santificação. A dor moral é a forma maior de expurgar o pecado na concepção aqui conceituado. Existirá para o homem, execução de pena maior que a dor? Existem várias formas de dor, e sem dúvidas a que mais calcifica o sofrimento, é a dor da separação. A separação para os que se amam é excelência da dor. É a dor suprema. Porquanto, todos trazemos uma culpa de um pecado anterior. Na verdade, a falta de conhecimento (ausência de Deus) nos conduz ao mal. À medida em que vamos adquirindo sabedoria (conhecimento de Deus) sofremos menos. A dor suprema a cada dia é aliviada pelo conhecimento de Deus. A conclusão a que chegamos é que sofremos mais quanto mais formos ignorantes, carentes de Deus. A sabedoria é o conhecimento elevado ao mais alto nível de moralidade é o êxtase do conhecimento de Deus. Eis o engano dos homens que teimam em colocar em lugares distintos e estanques o conhecimento e a moral, como asas para o vôo supremo. Em verdade, apenas uma asa é que desenha um anjo. A asa do conhecimento de Deus. A dor, é a eternização da ignorância. É necessário um esclarecimento. A dor e a tristeza são coisas distintas. O sublime às vezes verte uma lágrima, a Bíblia nos revela que Jesus chorou. A lágrima purifica a dor do seu semelhante, do seu irmão, do seu povo. A morte deixará de ser uma dor extrema com a nossa proximidade de Deus, com o desenvolvimento da nossa sabedoria, pois que nesta situação não estaremos mais a errar, a pecar, a agir de encontro ao amor, e não traremos mais a punição em nossos atos. Aqui relembro a Nova Jerusalém, que também não comporta um estudo neste artigo. Por derradeiro, cabe aqui a reflexão de que a morte espiritual impede o homem de ver o sobrenatural e Jesus veio para que o homem tenha vida e tenham em abundância. 
Fica assim o desafio para o Cristão quando descobre que a vida espiritual tem dimensões individuais e corpóreas: que mantenham em mente que a estrada conducente à vida é a estrada do amor, e o pecado, sendo um caminho, não deve ser percorrido pelo Cristão. Sendo o perdão uma atenuante por excelência, deve ser praticado, notadamente para aliviar o sofrimento alheio por condutas que se enquadram no conceito analítico de pecado.

\section{REFERÊNCIAS}

BAVINCK, Herman. Dogmática Reformada. v. 3, São Paulo: Cultura Cristã, 2012.

BERKHOF. Louis. Teologia Sistemática. $4^{\mathrm{a}}$ ed. São Paulo: Cultura Cristã, 2012.

BIÉLER, André. O pensamento Econômico e Social de Calvino. $2^{\text {a }}$ ed. São Paulo: Cultura Cristã, 2012.

PIPER, John. O Poder purificador de se viver pela fé na graça futura. São Paulo: Shedd Publicações, 2009.

GOHEEN, Michael W; BARTHOLOMEW, Craig G. Introdução à Cosmovisão Cristã: vivendo na intersecção entre a visão bíblica e a contemporânea. São Paulo: Vida Nova. 2016.

GOHEEN, Michael W; BARTHOLOMEW, Craig G. O Drama das Escrituras: encontrando o nosso lugar na história bíblica. São Paulo: Vida Nova, 2017.

THOMPSON, F. Charles. Bíblia Thompson: tradução João Ferreira de Almeida. São Paulo: Editora Vida, 2014.

ZAFFARONI. Eugenio Raúl; PIERANGELI, José Henrique. Manual de Direito Penal Brasileiro: Parte Geral. $2^{\text {a }}$ ed. São Paulo: Revista dos Tribunais, 1999. 